\title{
Foreword
}

\section{Thoracic Outlet Syndrome \\ Evaluation: Patience Is a Virtue}

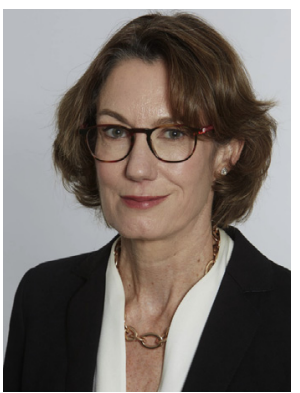

Virginia R. Litle, MD

Consulting Editor

We are excited to bring you a complete resource guide to help you care for your patient with thoracic outlet syndrome (TOS), a challenging diagnosis requiring multidisciplinary management and a cautious, thoughtful, preoperative evaluation. Thoracic surgeons Dean M. Donahue and Hugh G. Auchincloss have invited other thoracic peers, vascular surgeons, physical therapists, and radiologists to contribute to their focused issue. We are reminded of the complexity of this disease and that TOS is one of the few areas in general thoracic surgery that overlap, in particular, with our vascular surgery colleagues.

Surgeons are programmed to make a diagnosis and then book a procedural solution; however, TOS is one problem for which hasty decision making must be kept at bay, and patience is a virtue for the patients.

Thank you to our contributors and to our guest editors, Drs Donahue and Auchincloss. May they continue to educate us on this complex topic with more timely publications, including roboticassisted approaches, interventional radiology therapeutic indications, and TOS diagnosis in the time of a pandemic! We hope you will enjoy this issue!

Virginia R. Litle, MD Division of Thoracic Surgery

Department of Surgery

Boston University

88 East Newton Street Collamore Building, Suite 7380 Boston, MA 02118, USA

E-mail address:

Virginia.litle@bmc.org

Twitter: @vlitlemd (V.R. Litle) 